\title{
Supressão da produção de sementes de arroz-vermelho pela aplicação de herbicidas em arroz irrigado(1)
}

\begin{abstract}
Dirceu Agostinetto(2), Nilson Gilberto Fleck ${ }^{(3)}$, Valmir Gaedke Menezes ${ }^{(4)}$ e Emerson Luis Nunes Costa(3)
Resumo - A similaridade morfológica existente entre arroz-vermelho e arroz cultivado, associada à prolífica produção de sementes pelo arroz daninho e ao degrane dos grãos com elevado teor de umidade, são fatores que contribuem para sua infestação em lavouras de arroz. O objetivo deste trabalho foi investigar a supressão da produção de sementes viáveis, pelo arroz-vermelho, a fim de reduzir o seu banco de sementes no solo. Para isso, conduziram-se experimentos no campo e em laboratório, nas estações de crescimento 1997/98 e 1998/99, utilizando-se os herbicidas não-seletivos glyphosate, glufosinate e paraquat, aplicados em duas épocas e em duas doses, e o regulador de crescimento, hidrazida maléica, testado em duas épocas. Incluiu-se uma testemunha que não recebeu aplicação. Utilizou-se a cultivar de arroz IRGA-416, que cresceu na presença de elevada infestação de arrozvermelho. Os produtos químicos foram aplicados na fase de maturação fisiológica da cultura. As variáveis avaliadas no arroz-vermelho foram: número de colmos sem panícula, com panículas normais e estéreis, esterilidade de espiguetas, produção de sementes, peso médio de grãos e germinação de sementes. Os herbicidas glyphosate, glufosinate e paraquat podem ser usados seletivamente para suprimir a produção de sementes de arroz-vermelho, quando aplicados na fase de maturação do arroz irrigado. A adoção desta tecnologia depende de haver diferença de ciclo do arroz-vermelho em relação ao cultivado, pela utilização de cultivares de arroz de ciclo precoce ou superprecoce.
\end{abstract}

Termos para indexação: Oryza sativa, dessecantes, controle de plantas daninhas, substâncias de crescimento vegetal.

\section{Suppression of red rice seed production by herbicides applied to irrigated rice}

\begin{abstract}
Morphological similarity between red rice and cultivated rice, associated with a prolific seed production by weedy rice and to grain dehiscence with high moisture content, are factors that contribute to its invasion in rice fields. The objective of this research was to investigate the suppression of viable seed production by red rice, with the intent of reducing its seed bank in the soil. With this purpose, field and laboratory experiments were carried out during the growing seasons of 1997/98 and 1998/99, utilizing the non-selective herbicides glyphosate, glufosinate, and paraquat, applied at two times and at two rates, and the growth regulator maleic hydrazide, tested at two times. A control without chemical treatment was included. The rice cultivar tested was IRGA-416, grown in the presence of a high red rice infestation. The chemicals were applied at physiological maturity of cultivated rice. Variables evaluated in red rice were: numbers of stems without panicle, with normal panicles, and sterile ones, spikelets sterility, seed production, seed weight and germination. The herbicides glyphosate, glufosinate, and paraquat can be used selectively in order to suppress red rice seed production when applied during maturity phase of cultivated rice. Adoption of this technology depends on existence of difference between maturity of cultivated and weedy rice, through use of early maturity rice cultivars.
\end{abstract}

Index terms: Oryza sativa, desiccants, weed control, plant growth substances.

\footnotetext{
(1) Aceito para publicação em 23 de novembro de 2000.

(2)Universidade Federal do Rio Grande do Sul (UFRGS), Faculdade de Agronomia, Caixa Postal 776, CEP 91501-970 Porto Alegre, RS. E-mail: dirceua@vortex.ufrgs.br
}

(3)UFRGS, Faculdade de Agronomia, Dep. de Plantas de Lavoura. Bolsista do CNPq. E-mail: fleck@vortex.ufrgs.br, elncosta@vortex.bol.com.br

(4) Instituto Rio-Grandense do Arroz, Rua João Paetzel, 723, CEP 91330-280 Porto Alegre, RS.

E-mail: irgafito@pro.via-rs.com.br 


\section{Introdução}

A produtividade média de arroz no Rio Grande do Sul cresceu, nas últimas décadas, atingindo patamar de 5,8 $\mathrm{t} \mathrm{ha}^{-1}$ no ano de 1999 (Irga, 1999). No entanto, o fator que mais se destaca como limitante ao aumento do potencial de rendimento é o controle insatisfatório de plantas daninhas, especialmente do arroz-vermelho, o que ainda causa elevadas reduções na produção do cereal.

A competição acentua-se à medida que aumenta a diferença entre a altura da cultura e a da invasora, sendo atingido o efeito máximo durante os estádios de florescimento e enchimento de grãos do arroz (Fischer \& Ramirez, 1993). A redução do rendimento, causada pela competição do arroz-vermelho com o arroz cultivado, varia com o nível de infestação, condições edafoclimáticas, características da cultivar, período de convivência e biótipo da invasora encontrado na área (Montealegre \& Vargas, 1989). A habilidade competitiva do arroz-vermelho e seu estabelecimento como planta daninha podem ser explicados pela alta capacidade de produção de fitomassa, estatura elevada de suas plantas, ciclo mais longo que o da maioria das cultivares, queda precoce e dormência das sementes, e sua viabilidade no solo por vários anos (Diarra et al., 1985).

Devido às similaridades morfofisiológicas existentes entre o arroz-vermelho e o cultivado, sua eliminação torna-se difícil, e o controle em níveis satisfatórios, através de um único método, se torna praticamente inviável. Deste modo, seu controle requer a integração de múltiplas ações, como: emprego de sementes certificadas, preparo antecipado do solo com semeadura direta, uso de sementes pré-germinadas, adoção da rotação de culturas, revolvimento do solo durante o pousio, incorporação de herbicidas em pré-semeadura (Marchezan, 1994), aumento da densidade de semeadura, uso de menor espaçamento entre linhas e aplicação do regulador de crescimento hidrazida maléica.

$\mathrm{O}$ acréscimo de sementes no banco ocorre, principalmente, através da produção de sementes pelas plantas estabelecidas no local (Carmona, 1992). Portanto, prevenir a produção de sementes de arroz-vermelho constitui a meta básica a incluir nas práticas de controle. $\mathrm{O}$ uso de herbicidas para suprimir a pro- dução de sementes viáveis que retornam ao solo pode apresentar benefícios definitivos a longo prazo, em programas de controle de arroz-vermelho. Vários relatos aparecem na literatura referindo que herbicidas aplicados durante estádios reprodutivos de plantas daninhas reduzem a produção e a viabilidade das sementes em diversas espécies, ou então, afetam a progênie oriunda das sementes produzidas (Biniak \& Aldrich, 1986; Andres \& Fleck, 1994; Madafiglio et al., 1997). A aplicação seletiva no tempo de produtos químicos durante a fase inicial de formação das sementes do arroz-vermelho, quando as sementes do arroz cultivado já estiverem num estádio seguro, pode reduzir a produção de sementes viáveis pelo arroz-vermelho. Em conseqüência, os produtos químicos não prejudicariam a produtividade do arroz cultivado e tampouco a formação de suas sementes.

Este trabalho teve por objetivo investigar a possibilidade de suprimir por via química a produção de sementes viáveis do arroz-vermelho, a fim de buscar a redução do banco de sementes desta invasora no solo, em áreas de lavouras de arroz cultivado.

\section{Material e Métodos}

A pesquisa foi conduzida durante dois anos, e dividida em duas etapas: A primeira foi realizada no campo, nas estações de crescimento 1997/98 e 1998/99, em área da Estação Experimental do Arroz (EEA), pertencente ao Instituto Rio-Grandense do Arroz (Irga), localizada no $\mathrm{Mu}$ nicípio de Cachoeirinha, RS; a segunda foi realizada em laboratório, no Departamento de Plantas de Lavoura da Faculdade de Agronomia da Universidade Federal do Rio Grande do Sul (UFRGS), em Porto Alegre, RS.

O solo da área experimental da EEA/Irga é classificado como Planossolo hidromórfico; pertence à unidade de mapeamento Vacacaí (Embrapa, 1999). Anteriormente à instalação do primeiro experimento, a área foi sistematizada (em nível, com canais de irrigação, drenos e taipas), permanecendo em pousio. No primeiro ano da pesquisa, o delineamento experimental utilizado foi o de blocos casualizados, com quatro repetições por tratamento. Cada bloco constou de 15 tratamentos, e cada unidade experimental apresentou área de $13,5 \mathrm{~m}^{2}(3 \times 4,5 \mathrm{~m})$. O delineamento experimental usado no segundo ano foi completamente casualizado, com quatro repetições por tratamento. As unidades experimentais foram compostas por áreas de $12 \mathrm{~m}^{2}(2 \times 6 \mathrm{~m})$. Os tratamentos testados no se- 
gundo ano foram idênticos aos do primeiro ano (Tabela 1).

Os produtos químicos usados dividem-se em duas categorias: a dos herbicidas não-seletivos, também referidos como dessecantes, a saber: glyphosate [ $\mathrm{N}$-(fosfonometil) glicina], glufosinate [ácido 2-amino-4(hidroximetilfosfinil) butanóico] e paraquat (ion 1,1'-dimetil-4,4'bipiridinio); e a do regulador de crescimento hidrazida maléica (1,2-dihidro-3,6-piridazinadiona). O tratamento químico padrão utilizado como comparativo aos herbicidas não-seletivos foi a hidrazida maléica, a qual foi aplicada em duas épocas. Os produtos foram aplicados durante um período de 5 a 6 dias; essa aplicação coincidiu, aproximadamente, com a fase de maturação fisiológica do arroz cultivado.

O preparo do solo, em ambos os anos, foi realizado segundo o sistema convencional. Objetivando garantir o estabelecimento da população do arroz-vermelho, este foi semeado a lanço, na densidade aproximada de 100 sementes $\mathrm{m}^{-2}$, realizando-se, então, nova gradagem, para incorporação das sementes, finalizando-se o preparo do solo com a passagem de rolo canelado. A população média de arroz-vermelho que se desenvolveu na área experimental foi equivalente a 71 e 248 plantas $\mathrm{m}^{-2}$, no primeiro e segundo ano, respectivamente.

Aplicaram-se, em cobertura, $70 \mathrm{~kg} \mathrm{ha}^{-1} \mathrm{de} \mathrm{N}$, na forma de uréia, divididas em duas aplicações, aos 16 e 34 dias após a emergência (DAE) do arroz cultivado. A cultivar utilizada foi IRGA-416, que apresenta como principais características: ciclo precoce (até 120 dias), estatura baixa (menos de $100 \mathrm{~cm}$ ), alta capacidade de afilhamento, e resistência ao acamamento. A semeadura foi realizada em linhas, na densidade de 400 sementes $\mathrm{m}^{-2}$, nos dias 17 de dezembro de 1997 e 19 de novembro de 1998, para primeira e segunda estações de crescimento, respectivamente.

Dois dias antes de se iniciar a irrigação (10 DAE), aplicou-se uma mistura, em tanque, dos herbicidas quinclorac + propanil + pyrazosulfuron, para controlar as plantas daninhas que se desenvolveram (exceto arroz-vermelho). A supressão da irrigação foi realizada quando as plantas do arroz cultivado encontravam-se em maturação de colheita (umidade dos grãos de $22 \%$ ). No segundo ano, em face da ocorrência da praga bicheira da raiz do arroz (Oryzophagus oryzae), aplicou-se o inseticida carbofuran aos 43 DAE.

As aplicações dos produtos químicos (tratamentos) foram realizadas no horário compreendido entre as $10 \mathrm{~h} \mathrm{e}$ as $11 \mathrm{~h} 30$, utilizando-se um pulverizador costal de precisão, com bicos de jato plano em leque, da série 110.03, mantendo-se pressão constante de $150 \mathrm{kPa}$, e velocidade de deslocamento de $3,6 \mathrm{~km} \mathrm{~h}^{-1}$, o que propiciou a aplica- ção de um volume de calda de $200 \mathrm{~L} \mathrm{ha}^{-1}$. Na aplicação do paraquat foi utilizado o adjuvante Agral na concentração de $0,1 \% \mathrm{v} / \mathrm{v}$.

No primeiro ano, a colheita do arroz foi realizada em duas épocas: 99 DAE, nos tratamentos 1 a 12, e 105 DAE, nos tratamentos 13,14 e 15 . No segundo ano, a colheita ocorreu aos 106 DAE nos tratamentos 1 a 12, e 111 DAE, nos tratamentos 13,14 e 15 . O atraso na colheita dos tratamentos 13,14 e 15 objetivou propiciar que os grãos do arroz cultivado atingissem umidade de colheita (22\%).

A quantificação das variáveis números de colmos de arroz-vermelho sem panícula, de panículas normais e estéreis foi realizada por meio de duas contagens em áreas de $0,25 \mathrm{~m}^{2}$ por unidade experimental. A esterilidade de espiguetas por panícula foi obtida pela contagem de grãos não-formados, em uma amostra de dez panículas coletadas aleatoriamente na área útil de cada unidade experimental. Para determinar a produção de sementes por área, foram previamente ensacadas dez panículas de arroz-vermelho em cada unidade experimental. Após a trilhagem das panículas, as sementes formadas foram separadas das espiguetas estéreis, e então, contadas. $\mathrm{O}$ total de sementes formadas foi multiplicado pelo número de panículas normais por metro quadrado. O peso médio de sementes, determinado somente na segunda estação de crescimento, foi obtido com a pesagem de cinco subamostras de 100 sementes de cada unidade experimental. Para isso, foram trilhadas todas as panículas colhidas em cada parcela, e separadas as sementes cheias das espiguetas estéreis. O teste de germinação das sementes de arroz-vermelho foi efetuado de acordo com as regras para análise de sementes (Brasil, 1992), aos 197 e 227 dias após a colheita no primeiro e no segundo ano, respectivamente.

No presente experimento, considera-se como semente o fruto (cariopse) ou grão de arroz formado pelo embrião, endosperma, tegumento, pericarpo e casca (pálea e lema). Assim, o termo semente é usado apenas no sentido agronômico, para designar a unidade de propagação do arrozvermelho.

Os dados obtidos foram submetidos à análise de variância, pelo teste $\mathrm{F}$, e as médias comparadas pelo teste de Duncan a 5\% de probabilidade. Os valores expressos em porcentagem foram transformados em arco seno da raiz quadrada de cada observação, antes de serem submetidos à análise de variância.

\section{Resultados e Discussão}

Considerando-se os resultados obtidos no primeiro ano, o número de colmos de arroz-vermelho desprovidos de panículas foi maior nos tratamentos com 
glyphosate e com hidrazida maléica aplicada na primeira época, comparativamente à testemunha (Tabela 1). Os tratamentos que mais afetaram a emissão de panículas foram os que receberam glyphosate na dose de $720 \mathrm{~g} \mathrm{ha}^{-1}$, em ambas as épocas, e hidrazida maléica na primeira época. Os primeiros reduziram, em média, 11 vezes a formação de panículas, quando em comparação com a testemunha, enquanto o último reduziu a variável em 8,5 vezes. Em geral, os tratamentos com glufosinate ou paraquat não diferiram da testemunha ou da hidrazida maléica testada na primeira época.

Na segunda estação de crescimento, os maiores números de colmos de arroz-vermelho sem panícula foram observados nas unidades experimentais tratadas com glyphosate na primeira época. Nenhum dos demais tratamentos herbicidas diferiu da testemunha ou do padrão hidrazida maléica. Para tais resultados contribuiu o elevado coeficiente de variação constatado. Em média, os dois tratamentos com glyphosate aplicados na primeira época reduziram em cerca de 20 vezes o número de panículas emitidas. Compa- rando-se as duas estações de crescimento, verificase que, em ambas, os tratamentos com glyphosate foram os que apresentaram maior efeito supressivo na emissão de panículas pelo arroz-vermelho.

Com relação ao número de panículas normais, no primeiro ano verificou-se diferença significativa entre a testemunha e todos os demais tratamentos que receberam produtos químicos, os quais reduziram acentuadamente a formação de panículas. Cabe destacar que a maioria dos tratamentos com glyphosate reduziu pelo menos em 30 vezes o número de panículas em relação à testemunha.

No segundo ano, o número de panículas normais emitidas em todos os tratamentos químicos testados também foi inferior ao da testemunha. Contudo, na maioria dos casos, não houve diferenças significativas entre tratamentos com herbicidas não-seletivos. Plantas aspergidas com hidrazida maléica na segunda época, embora apresentassem valor significativamente inferior ao da testemunha, apresentaram, contudo, maior número de panículas normais do que com aplicação na primeira época e também em relação

Tabela 1. Efeito de produtos químicos aplicados na fase de maturação do arroz cultivado sobre número de colmos sem panícula e número de panículas normais de arroz-vermelho. EEA/IRGA, Cachoeirinha, $\operatorname{RS}^{(1)}$.

\begin{tabular}{|c|c|c|c|c|c|c|}
\hline \multirow[t]{2}{*}{ Tratamento } & \multirow{2}{*}{$\begin{array}{c}\text { Dose } \\
\left.\text { ( } \mathrm{g} \mathrm{ha}^{-1} \text { de i.a. }\right)\end{array}$} & \multirow{2}{*}{$\begin{array}{l}\text { Umidade dos } \\
\text { grãos }(\%)^{(2)}\end{array}$} & \multicolumn{2}{|c|}{ Colmos sem panícula $\left(\mathrm{n}^{\mathrm{o}} \mathrm{m}^{-2}\right)$} & \multicolumn{2}{|c|}{ Panículas normais $\left(\mathrm{n}^{\mathrm{o}} \mathrm{m}^{-2}\right.$} \\
\hline & & & $1997 / 98$ & 1998/99 & $1997 / 98$ & $1998 / 99$ \\
\hline Glyphosate & 720 & $34^{(3)}$ & $52 \mathrm{a}$ & $100 \mathrm{a}$ & $4 c$ & $7 \mathrm{de}$ \\
\hline Glyphosate & 1.440 & $34^{(3)}$ & $32 \mathrm{bc}$ & $97 \mathrm{a}$ & $5 \mathrm{c}$ & $2 \mathrm{e}$ \\
\hline Glyphosate & 720 & $30^{(4)}$ & $37 \mathrm{ab}$ & $29 b$ & $12 \mathrm{bc}$ & $19 \mathrm{cde}$ \\
\hline Glyphosate & 1.440 & $30^{(4)}$ & $27 \mathrm{bcde}$ & $15 \mathrm{~b}$ & $5 c$ & $9 \mathrm{de}$ \\
\hline Glufosinate & 200 & $30^{(4)}$ & 9def & $10 b$ & $13 b c$ & $14 \mathrm{cde}$ \\
\hline Glufosinate & 400 & $30^{(4)}$ & $28 \mathrm{bcd}$ & $11 \mathrm{~b}$ & $11 \mathrm{bc}$ & $7 \mathrm{de}$ \\
\hline Glufosinate & 200 & $28^{(5)}$ & $6 f$ & $9 b$ & $35 \mathrm{bc}$ & $20 \mathrm{cde}$ \\
\hline Glufosinate & 400 & $28^{(5)}$ & $13 \mathrm{cdef}$ & $10 \mathrm{~b}$ & $26 \mathrm{bc}$ & $20 \mathrm{cde}$ \\
\hline Paraquat & 200 & $30^{(4)}$ & 10def & $20 b$ & $15 \mathrm{bc}$ & $17 \mathrm{cde}$ \\
\hline Paraquat & 400 & $30^{(4)}$ & 10def & $10 \mathrm{~b}$ & $2 c$ & $14 \mathrm{cde}$ \\
\hline Paraquat & 200 & $28^{(5)}$ & 23 bcdef & $9 b$ & $45 b$ & $37 \mathrm{c}$ \\
\hline Paraquat & 400 & $28^{(5)}$ & 7ef & $16 b$ & $22 b c$ & $31 \mathrm{~cd}$ \\
\hline Hidrazida maléica & 1.800 & $34^{(3)}$ & $34 \mathrm{ab}$ & $8 b$ & $12 \mathrm{bc}$ & $26 \mathrm{cde}$ \\
\hline Hidrazida maléica & 1.800 & $30^{(4)}$ & 9def & $12 b$ & $19 b c$ & $94 \mathrm{~b}$ \\
\hline Testemunha & & & $4 \mathrm{f}$ & $5 b$ & $153 \mathrm{a}$ & $390 \mathrm{a}$ \\
\hline CV (\%) & & & 62,4 & 80,9 & 85,1 & 32,9 \\
\hline
\end{tabular}

${ }^{(1)}$ Em cada coluna, médias seguidas pela mesma letra não diferem entre si pelo teste de Duncan a 5\% de probabilidade. ${ }^{(2)}$ Umidade na época da aplicação dos produtos químicos. ${ }^{(3)}$ Arroz cultivado em estádio de grãos pastosos a duros e arroz-vermelho em estádio de emissão de panículas. ${ }^{(4)}$ Arroz cultivado em estádio de grãos duros e arroz-vermelho em estádio de floração plena. ${ }^{(5)}$ Arroz cultivado em estádio de grãos duros e arroz-vermelho em estádio de grãos leitosos no terço superior das panículas. 
aos demais tratamentos químicos. De modo semelhante ao constatado no primeiro ano, os tratamentos com glyphosate foram os que mais afetaram a produção de panículas normais, os quais, em média, reduziram a variável em 42 vezes.

O número de panículas estéreis de arroz-vermelho, no primeiro ano da pesquisa, foi maior nos tratamentos com produtos químicos em relação à testemunha, com exceção de dois casos (hidrazida maléica aplicada na segunda época e glyphosate a $720 \mathrm{~g} \mathrm{ha}^{-1}$ aplicado na primeira época) (Tabela 2). Na segunda estação de crescimento, observou-se resultado semelhante, pois todos os tratamentos químicos apresentaram maior número de panículas estéreis do que a testemunha, ocasionando drástica esterilidade na formação de panículas. Os tratamentos com glyphosate (720 e $1.440 \mathrm{~g} \mathrm{ha}^{-1}$ ), aplicados na primeira época, apresentaram os menores efeitos, mas eles não diferiram da hidrazida maléica aplicada na segunda época. Contudo, o menor número de panículas estéreis verificado nos tratamentos de glyphosate aplicados na primeira época deve-se, em parte, ao maior número de colmos sem panícula observados nos mesmos tratamentos (Tabela 1).
Quanto à esterilidade das espiguetas, em ambas as estações de crescimento verificou-se que todos os produtos químicos, independentemente da dose ou da época de aplicação, aumentaram a variável em comparação à testemunha (Tabela 2). A esterilidade das espiguetas, relativamente elevada, verificada no tratamento-testemunha, deveu-se a que muitas delas ainda se encontravam no estádio de grãos leitosos por ocasião da colheita do experimento, impedindo uma precisa quantificação da variável.

Herbicidas aplicados no final do ciclo das invasoras podem reduzir a produção de panículas ou de sementes normais e, conseqüentemente, reduzir o reabastecimento das reservas de sementes no solo. As diferenças relativas à época de aplicação na eficácia herbicida podem estar relacionadas ao estádio de desenvolvimento do embrião imaturo (Isaacs et al., 1989). Segundo os autores, a divisão celular no embrião é rápida no período seguinte à fecundação, mas diminui e cessa antes de o embrião atingir metade do seu peso máximo. Esse fato pode explicar os resultados constatados, de que aplicações de herbicidas realizadas nos estádios iniciais de desenvolvimento reprodutivo apresentam maior efeito na supressão da

Tabela 2. Efeito de produtos químicos aplicados na fase de maturação do arroz cultivado sobre número de panículas estéreis e esterilidade de espiguetas de arroz-vermelho. EEA/IRGA, Cachoeirinha, $\operatorname{RS}^{(1)}$.

\begin{tabular}{|c|c|c|c|c|c|c|}
\hline \multirow[t]{2}{*}{ Tratamento } & \multirow{2}{*}{$\begin{array}{c}\text { Dose } \\
\text { ( } \mathrm{g} \mathrm{ha}^{-1} \text { de i.a.) }\end{array}$} & \multirow{2}{*}{$\begin{array}{l}\text { Umidade dos } \\
\text { grãos }(\%)^{(2)}\end{array}$} & \multicolumn{2}{|c|}{ Panículas estéreis $\left(\mathrm{n}^{\mathrm{o}} \mathrm{m}^{-2}\right)$} & \multicolumn{2}{|c|}{ Esterilidade (\%) } \\
\hline & & & $1997 / 98$ & $1998 / 99$ & $1997 / 98$ & 1998/99 \\
\hline Glyphosate & 720 & 34 & $31 \mathrm{bc}$ & $167 \mathrm{e}$ & $96,1 b$ & $97,0 \mathrm{abc}$ \\
\hline Glyphosate & 1.440 & 34 & $63 \mathrm{ab}$ & $182 \mathrm{e}$ & $99,9 \mathrm{ab}$ & $99,6 a b$ \\
\hline Glyphosate & 720 & 30 & 74ab & $252 \mathrm{~cd}$ & $99,2 \mathrm{ab}$ & $99,7 \mathrm{ab}$ \\
\hline Glyphosate & 1.440 & 30 & $71 \mathrm{ab}$ & $270 \mathrm{bcd}$ & $100,0 \mathrm{a}$ & $99,7 \mathrm{ab}$ \\
\hline Glufosinate & 200 & 30 & $107 \mathrm{a}$ & $316 a b c$ & $99,2 \mathrm{ab}$ & $99,9 a$ \\
\hline Glufosinate & 400 & 30 & $66 a b$ & $324 a b c$ & $99,6 \mathrm{ab}$ & $99,8 \mathrm{a}$ \\
\hline Glufosinate & 200 & 28 & $88 \mathrm{ab}$ & $330 \mathrm{ab}$ & $97,9 \mathrm{ab}$ & $95,7 b c$ \\
\hline Glufosinate & 400 & 28 & $75 \mathrm{ab}$ & 336ab & $96,8 \mathrm{ab}$ & $99,1 \mathrm{ab}$ \\
\hline Paraquat & 200 & 30 & $96 a b$ & 292abcd & $100,0 \mathrm{a}$ & $98,9 \mathrm{ab}$ \\
\hline Paraquat & 400 & 30 & $116 \mathrm{a}$ & $345 \mathrm{a}$ & $100,0 \mathrm{a}$ & $99,0 \mathrm{ab}$ \\
\hline Paraquat & 200 & 28 & $100 \mathrm{a}$ & $268 \mathrm{bcd}$ & $99,9 \mathrm{ab}$ & $93,5 \mathrm{c}$ \\
\hline Paraquat & 400 & 28 & $94 \mathrm{ab}$ & $301 \mathrm{abc}$ & $99,6 \mathrm{ab}$ & $99,2 \mathrm{ab}$ \\
\hline Hidrazida maléica & 1.800 & 34 & $72 \mathrm{ab}$ & 294abcd & $100,0 \mathrm{a}$ & $95,6 \mathrm{bc}$ \\
\hline Hidrazida maléica & 1.800 & 30 & $56 a b c$ & $226 \mathrm{de}$ & $98,4 \mathrm{ab}$ & $90,0 \mathrm{c}$ \\
\hline Testemunha & & & $0 \mathrm{c}$ & Of & $53,6 \mathrm{c}$ & $42,7 \mathrm{~d}$ \\
\hline CV (\%) & & & 53,9 & 17,2 & 7,3 & 6,8 \\
\hline
\end{tabular}


emissão de panículas. Esse foi o caso com os tratamentos de glyphosate e de hidrazida maléica aplicados antecipadamente à emissão de panículas de arroz-vermelho.

No presente experimento, as diferenças nos próprios mecanismos de ação dos herbicidas testados podem explicar grande parte dos resultados obtidos. Segundo Ahrens (1994), glyphosate é absorvido moderadamente pela cutícula, sendo translocado primariamente no simplasto e, em algumas situações, tem sido observada translocação apoplástica. Logo após sua aplicação, ocorre inibição do crescimento vegetal e sua ação é seguida por clorose e necrose generalizadas dentro de 4 a 7 dias em gramíneas suscetíveis. Doses subletais de glyphosate inibem a emergência de panículas na maioria das espécies gramíneas. Por outro lado, glufosinate apresenta movimento limitado pelo xilema e floema, e cerca de 3 a 5 dias após aplicação ocorre clorose e murcha foliares, seguidas por necrose. Já o paraquat, embora seja rapidamente absorvido pela folhagem, transloca-se apenas no apoplasto (incluindo xilema) e, desta forma, permanece nas folhas tratadas em condições normais (Ahrens, 1994). No caso da hidrazida maléica, o composto inibe a divisão celular, tanto na mitose quanto na meiose, mas não atua no alongamento celular, e quando aplicada em fase de emborrachamento poderá inibir a extrusão das panículas (Ahrens, 1994).

A produção de sementes de arroz-vermelho por área, representando o potencial de reabastecimento do banco de sementes no solo, não diferiu significativamente entre os produtos químicos testados, mas em todas as situações eles reduziram drasticamente a produção de sementes, em ambas as estações de crescimento (Tabela 3). Constatou-se que no segundo ano a produção de sementes de arroz-vermelho foi cerca de 2,4 vezes maior do que a estimada no primeiro ano, como resultado direto da maior população de plantas que se estabeleceu naquela safra. Em comparação ao tratamento-testemunha, as produções de sementes de arroz-vermelho, oriundas das unidades experimentais aspergidas com herbicidas não-seletivos, variaram entre $0 \%$ e $3 \%$ no primeiro ano, e entre $0 \%$ e $1 \%$ no segundo ano, do potencial máximo de produção. Esses resultados representam uma queda considerável de sementes que poderiam reabastecer o banco no solo ou contaminar as sementes da cultura ou a produção comercial do cereal. No primeiro ano, a produtividade de grãos de arrozvermelho foi equivalente a $2.560 \mathrm{~kg} \mathrm{ha}^{-1}$, aumentando em $3.500 \mathrm{~kg} \mathrm{ha}^{-1}$ no segundo ano, atingindo, portanto, a cifra de $6.060 \mathrm{~kg} \mathrm{ha}^{-1}$, um acréscimo de $137 \%$ (Tabela 3).

A elevada quantidade de sementes de arroz-vermelho que reabastecem o seu banco de sementes é o principal fator limitante ao cultivo de arroz na mesma área, por anos seguidos, no Rio Grande do Sul. Isso condiciona que em muitas áreas, a cada cinco anos, somente dois sejam cultivados com arroz, deixando-se em pousio no período restante para diminuição do banco de sementes. A redução da produção de sementes de arroz-vermelho obtida no presente experimento possibilita cultivar arroz em anos seguidos; porém, a permanência de sementes viáveis da invasora no solo por longo período de tempo e o escape ao tratamento de plantas de arroz-vermelho, que apresentem ciclo de desenvolvimento igual ou menor ao do arroz cultivado, inviabilizam a utilização da área para produção de sementes.

Resultados relatados em diversos trabalhos demonstram que herbicidas aplicados durante o florescimento das plantas daninhas podem proporcionar grande redução na produção de sementes e, também, na sua viabilidade (Isaacs et al., 1989; Madafiglio et al., 1997; Taylor \& Oliver, 1997). Assim, Biniak \& Aldrich (1986) verificaram que glyphosate aplicado no início da emissão de panículas de Setaria faberi (capim rabo-de-raposa) infestando soja, reduziu em $96 \%$ a produção de sementes da espécie.

A utilização de herbicidas não-seletivos ao final do ciclo do arroz, além de apresentar custo do produto três a quatro vezes menor do que o da hidrazida maléica, ainda permite antecipar a colheita. Além disso, esses herbicidas, por apresentarem efeito dessecante, favorecem a instalação antecipada de espécies forrageiras ou de cobertura do solo, devido à redução da relação $\mathrm{C} / \mathrm{N}$ da resteva e conseqüente menor imobilização do $\mathrm{N}$ pelos microrganismos do solo, aumentando sua disponibilidade para a cultura posterior (Aita \& Ros, 1996). Por outro lado, ocorre perda do potencial de uso da resteva pela ação dessecante dos herbicidas, o que inviabiliza seu em- 
prego para pastoreio com bovinos, prática comumente utilizada pelos orizicultores no Estado.

O peso médio de sementes de arroz-vermelho, determinado apenas na segunda estação de crescimento, em todos os tratamentos químicos, foi menor do que o da testemunha (Tabela 3). Hidrazida maléica aplicada na segunda época, embora tenha apresentado valor inferior ao da testemunha, superou o peso de sementes dos demais tratamentos herbicidas. Entre os herbicidas dessecantes, o maior peso de sementes foi observado nos tratamentos com paraquat, e o menor, nos tratamentos com glyphosate. Em média, o peso de sementes dos tratamentos com glyphosate foi $48 \%$ menor do que o da testemunha, enquanto o peso médio das sementes que receberam aplicações de paraquat foi apenas $30 \%$ inferior ao da testemunha.

O atraso na aplicação dos dessecantes devido ao maior teor de umidade nos grãos, e as diferenças entre épocas de aplicação e entre mecanismos de ação dos herbicidas podem explicar a discordância observada entre os trabalhos. Por ocasião das aplicações de glyphosate, as plantas de arroz-vermelho encontravam-se em estádio de emissão de panículas e de floração plena, respectivamente. Para as aplicações de paraquat, as plantas apresentavam-se em estádio de floração plena e de grãos leitosos no terço superior das panículas, respectivamente.

Após a absorção do herbicida glyphosate pelas plantas, o composto é translocado e atua em diferentes partes; o paraquat atua próximo ao local de absorção (Ahrens, 1994). Desta forma, o atraso ocorrido nas aplicações e as diferenças entre épocas e a ação de contato do paraquat propiciaram maior produção de panículas e de sementes normais até o momento da aplicação e, conseqüentemente, as sementes apresentaram maior peso. Por outro lado, o glyphosate, ao exercer ampla translocação, mostra ação lenta, e pelo fato de a aplicação na primeira época ter sido realizada antes do paraquat, provavelmente permitiu às plantas acumular mais reservas nas sementes durante maior período de tempo, até ocorrer a morte completa das plantas. Assim, as sementes formadas antes da aplicação de glyphosate apresentaram peso reduzido e, em sua maioria, foram descartadas pelo método de seleção adotado, o que resultou em menores valores absolutos de produção de sementes normais e em sementes com menor peso.

Analisando-se os resultados da germinação de arroz-vermelho, obtidos no primeiro ano, constataram-se diferenças significativas entre os tratamentos químicos e a testemunha (Tabela 3). Em geral, os pro-

Tabela 3. Efeito de produtos químicos aplicados na fase de maturação do arroz cultivado sobre a produção de sementes, peso de 1.000 sementes e germinação de arroz-vermelho. EEA/IRGA, Cachoeirinha, $\mathrm{RS}^{(1)}$.

\begin{tabular}{|c|c|c|c|c|c|c|c|}
\hline Tratamento & $\begin{array}{c}\text { Dose } \\
\left(\mathrm{g} \mathrm{ha}^{-1} \text { de i.a.) }\right.\end{array}$ & $\begin{array}{l}\text { Umidade } \\
\text { dos grãos } \\
(\%)^{(2)}\end{array}$ & \multicolumn{2}{|c|}{$\begin{array}{l}\text { Produção de sementes } \\
\left(\mathrm{n}^{\mathrm{o}} \mathrm{m}^{-2}\right)\end{array}$} & $\begin{array}{c}\text { Peso de } 1.000 \text { sementes } \\
(\mathrm{g}) \\
1998 / 99 \\
\end{array}$ & \multicolumn{2}{|c|}{$\begin{array}{c}\text { Germinação } \\
(\%)\end{array}$} \\
\hline Glyphosate & 720 & 34 & $37 b$ & $30 \mathrm{~b}$ & $17,1 \mathrm{efg}$ & $7 \mathrm{bcd}$ & $49 \mathrm{~cd}$ \\
\hline Glyphosate & 720 & 30 & $30 b$ & $8 b$ & $13,4 \mathrm{~h}$ & $1 \mathrm{~cd}$ & $42 \mathrm{de}$ \\
\hline Glyphosate & 1.440 & 30 & $0 \mathrm{~b}$ & $4 b$ & $14,0 \mathrm{~h}$ & $0 \mathrm{~d}$ & $38 \mathrm{def}$ \\
\hline Glufosinate & 200 & 30 & $10 b$ & $1 b$ & $17,8 \mathrm{def}$ & $14 b$ & $57 \mathrm{c}$ \\
\hline Glufosinate & 200 & 28 & $268 \mathrm{~b}$ & $67 b$ & $17,8 \mathrm{def}$ & 6bcd & $41 \mathrm{de}$ \\
\hline Glufosinate & 400 & 28 & $146 \mathrm{~b}$ & $24 b$ & $17,4 \mathrm{efg}$ & $10 \mathrm{bc}$ & $49 \mathrm{~cd}$ \\
\hline Paraquat & 200 & 30 & $1 \mathrm{~b}$ & $28 b$ & $20,0 \mathrm{~cd}$ & $1 \mathrm{~cd}$ & $3 \mathrm{gh}$ \\
\hline Paraquat & 400 & 30 & $0 b$ & $15 \mathrm{~b}$ & $19,5 \mathrm{cde}$ & $6 \mathrm{bcd}$ & $1 \mathrm{~g}$ \\
\hline Paraquat & 200 & 28 & $16 b$ & $228 \mathrm{~b}$ & $20,6 \mathrm{c}$ & $8 \mathrm{bcd}$ & $7 \mathrm{~g}$ \\
\hline Paraquat & 400 & 28 & $10 \mathrm{~b}$ & $25 \mathrm{~b}$ & $19,3 \mathrm{cde}$ & $5 \mathrm{bcd}$ & $5 \mathrm{gh}$ \\
\hline $\mathrm{CV}(\%)$ & & & 121,3 & 75,4 & 8,7 & 63,0 & 13,6 \\
\hline
\end{tabular}

(1)Em cada coluna, médias seguidas pela mesma letra não diferem entre si pelo teste de Duncan a 5\% de probabilidade. (2)Umidade na época de aplicação dos produtos químicos. 
dutos químicos testados foram eficientes em inviabilizar o processo de germinação das sementes de arroz-vermelho. Na segunda estação de crescimento, de modo similar à primeira, todos os tratamentos químicos originaram menores índices de germinação do que a testemunha não-tratada. Em geral, os tratamentos com glyphosate não diferiram do padrão hidrazida maléica aplicada na segunda época, enquanto os que utilizaram glufosinate geralmente superaram o produto padrão em germinação. Os tratamentos com paraquat foram os que mais afetaram a germinação do arroz-vermelho, reduzindo a variável em maior grau do que qualquer outro tratamento.

Os resultados obtidos no presente experimento coincidem com os referidos por Brandi \& Clari (1999), os quais verificaram que hidrazida maléica aplicada quando os grãos do terço médio das panículas da cultivar de arroz IRGA-416 se apresentavam no estádio leitoso e de massa firme reduziu a germinação em $97 \%$ e $86 \%$, respectivamente, em teste realizado seis meses após a colheita.

Métodos direcionados a atingir a viabilidade das sementes apresentam potencial ideal para reduzir o reabastecimento da população de sementes viáveis no solo (Andres \& Fleck, 1994). Assim, Biniak \& Aldrich (1986) demonstraram que glyphosate aplicado no estádio de início da emissão de panículas de Setaria faberi reduziram a germinação das sementes em 95\%. Aplicações em estádios mais tardios foram menos eficazes, mas ainda assim reduziram significativamente a produção de sementes da espécie.

Em relação à drástica redução na germinação das sementes de arroz-vermelho por ação de paraquat, ocorrida no segundo ano da pesquisa, outros autores também encontraram tal efeito em sementes de outras espécies. Conforme Egley \& Williams (1978), paraquat aplicado sobre as sementes de Echinochloa crusgalli (capim-arroz) e Sorghum halepense (capimmassambará), nas doses de 30, 125 e $250 \mathrm{~mL} \mathrm{~L}^{-1}$, inibiu a germinação; e quando o glyphosate foi aplicado sobre as sementes das espécies que se encontravam na superfície do solo, a emergência das plântulas não foi afetada.

A viabilidade de sementes de arroz-vermelho por longos períodos de tempo, associada ao escape de plantas aos métodos de controle empregados, propicia a manutenção ou o aumento do banco de sementes. Estas podem ser as causas de não se ter conse- guido reduzir ou eliminar a incidência de arroz-vermelho nas diversas regiões do Estado em que ocorre, apesar das práticas de manejo utilizadas normalmente nos cultivos de arroz. Uma única planta de arroz-vermelho pode produzir, potencialmente, 1.500 sementes por ano (Salzman et al., 1989); desta forma, é essencial obter controle eficiente ou supressão da produção de suas sementes. Hidrazida maléica aplicada em estádio avançado do desenvolvimento do arroz-vermelho, a fim de evitar o reabastecimento do banco de sementes, é uma técnica já utilizada e consolidada; entretanto, são raros os relatos de trabalhos que utilizaram herbicidas dessecantes com tal objetivo na cultura do arroz irrigado.

O benefício decorrente da supressão da produção de sementes de arroz-vermelho pela aplicação de herbicidas não-seletivos não será imediato, pois do banco de sementes remanescente no solo continuarão emergindo novas plântulas, sobre as quais o processo deverá se repetir. $O$ decréscimo da infestação será eficaz na medida em que se adotar continuadamente esta prática. Além disso, o método permitirá reduzir a infestação de arroz-vermelho ao longo dos anos, sem a necessidade de suspender a produção de arroz cultivado. Entretanto, o sucesso decorrente da utilização dessa tecnologia depende, fundamentalmente, do uso de cultivares de arroz de ciclo precoce ou superprecoce, pois, caso contrário, os efeitos serão nulos e, após cultivos sucessivos, poderá ocorrer seleção de biótipos de arroz-vermelho de ciclo curto, o que também inviabilizaria a utilização da técnica.

\section{Conclusões}

1. Os herbicidas glyphosate, glufosinate e paraquat podem ser usados para suprimir a produção de sementes de arroz-vermelho, quando aplicados na fase de maturação do arroz irrigado.

2. A adoção desta tecnologia depende de haver diferença de ciclo do arroz-vermelho e cultivado, pela utilização de cultivares de arroz de ciclo precoce ou superprecoce.

\section{Referências}

AHRENS, W. H. (Ed.). Herbicide handbook. Champaign: Weed Science Society of America, 1994. 352 p. 
AITA, C.; ROS, C. O. da. Efeito de espécies de inverno na cobertura do solo e fornecimento de nitrogênio ao milho em plantio direto. Revista Brasileira de Ciência do Solo, Campinas, v. 20, n. 1, p. 135-140, 1996.

ANDRES, A.; FLECK, N. G. Efeitos de herbicidas aplicados no período reprodutivo sobre o crescimento inicial de plantas daninhas na geração seguinte. Planta Daninha, Brasília, v. 12, n. 2, p. 70-77, 1994.

BINIAK, B. M.; ALDRICH, R. J. Reducing velvetleaf (Abutilon theophrasti) and giant foxtail (Setaria faberi) seed production with simulated-roller herbicide applications. Weed Science, Champaign, v. 34, n. 2, p. 256-259, 1986.

BRANDI, F.; CLARI, A. Redução da viabilidade de sementes de arroz-vermelho (Oryza sativa L.) com uso de hidrazida maléica (Fazor CS). In: CONGRESSO BRASILEIRO DE ARROZ IRRIGADO, 1.; REUNIÃO DA CULTURA DO ARROZ IRRIGADO, 23., 1999, Pelotas. Anais... Pelotas: Embrapa-CPACT, 1999. p. 497-499.

BRASIL. Ministério da Agricultura e Reforma Agrária. Coordenação de Laboratório Vegetal. Regras para análise de sementes. Brasília, 1992. 365 p.

CARMONA, R. Problemática e manejo de bancos de sementes de invasoras em solos agrícolas. Planta Daninha, Brasília, v. 10, n. 1/2, p. 5-16, 1992.

DIARRA, A.; SMITH JUNIOR, R. J.; TALBERT, R. E. Growth and morphological characteristics of red rice (Oryza sativa) biotypes. Weed Science, Champaign, v. 33, n. 3, p. 310-314, 1985.

EGLEY, G. H.; WILLIAMS, R. D. Glyphosate and paraquat effects on weed seed germination and seedling emergence. Weed Science, Champaign, v. 26, n. 2, p. 249251, 1978.

EMBRAPA. Centro Nacional de Pesquisa de Solos (Rio de Janeiro, RJ). Sistema brasileiro de classificação de solos. Rio de Janeiro, 1999. 412 p.
FISCHER, A. J.; RAMIREZ, A. Red rice (Oryza sativa): competition studies for management decisions. International Journal of Pest Management, London, v. 39, n. 2, p. 133-138, 1993.

IRGA. Divisão de Assistência Técnica e Extensão. Acompanhamento de colheita do arroz irrigado: safra 1998/ 99. Porto Alegre, 1999. 8 p.

ISAACS, M. A.; MURDOCK, E. C.; TOLER, J. E.; WALLACE, S. U. Effects of late-season herbicide applications on sicklepod (Cassia obtusifolia) seed production and viability. Weed Science, Champaign, v. 37, n. 6, p. 761-765, 1989.

MADAFIGLIO, G. P.; MEED, R. W.; SOLE, T. A. Evaluation of seed kill as a broadleaf weed control technique in wheat. In: BRIGHTON CROP PROTECTION CONFERENCE-WEEDS, 1997 , Brighton. Proceedings... Brighton: British Crop Protection Council, 1997. v. 3, p. 1031-1036.

MARCHEZAN, E. Arroz-vermelho: caracterização, prejuízos e controle. Ciência Rural, Santa Maria, v. 24, n. 2, p. 415-421, 1994.

MONTEALEGRE, F. A.; VARGAS, J. P. Efecto de algunas practicas culturales sobre la población de arroz rojo y los rendimientos del arroz comercial. Arroz, Bogotá, v. 38, n. 2, p. 19-24, 1989.

SALZMAN, F. P.; SMITH JUNIOR, R. J.; TALBERT, R. E. Control and seedhead suppression of red rice (Oryza sativa) in soybeans (Glycine max). Weed Technology, Champaign, v. 3, n. 2, p. 238-243, 1989.

TAYLOR, S. E.; OLIVER, L. R. Sicklepod (Senna obtusifolia) seed production and viability as influenced by late-season postemergence herbicide applications. Weed Science, Lawrence, v. 45, n. 2, p. 497-501, 1997. 